\title{
Conduta de acadêmicos de uma universidade da região amazônica frente ao bullying*
}

Recebido em: 19/01/2012

Aceito em: 12/07/2012
Maria Inês Ferreira de Miranda

Taís Regina Oliveira²

Pedro Di Tárique Barreto ${ }^{3}$

Maria das Graças Carvalho Ferriani ${ }^{4}$

Marcuce Antônio Miranda dos Santos 5

David Lopes Neto ${ }^{6}$

O estudo objetivou investigar os casos de violência nas relações dos acadêmicos a fim de conhecer a prevalência de bullying dentro da Universidade Federal de Rondônia-Campus Porto Velho. Tratou-se de um estudo quantitativo no qual foi efetuado um inquérito epidemiológico que consistiu em um delineamento de pesquisa que possibilitou conhecer as vivências de violência apresentadas pelos alunos de ensino superior da cidade em evidência. Para coleta de dados foi utilizado um questionário validado que foi aplicado durante visitas à Universidade, com alunos dos diversos cursos selecionados pela amostra quantitativa. Foram realizadas 456 entrevistas. Os resultados comprovaram que as manifestações de bullying ocorrem, principalmente, nas salas de aula (6,1\%). Também foi observado que $32 \%$ afirmaram já ter passado por uma situação que considerou humilhante ou constrangedora por parte dos docentes. Mediante aos achados desta pesquisa foi possível afirmar que as manifestações de bullying estão presentes nas relações sociais da universidade.

Descritores: Violência, Bullying, Ensino Superior.

\section{Behavior of students in a university of the amazon region faced with bullying}

This study aimed to investigate cases of violence in the relationship of academics to ascertain the prevalence of bullying within the Federal University of Rondônia, Porto Velho Campus. This was a quantitative study in which it was conducted a survey that consisted of a research design that helped us to understand the experiences of violence presented by the students of higher education from the city highlighted. For data collection we used a validated questionnaire that was applied during visits to the University with students from various courses selected by the sample quantity. 456 interviews were performed. Results showed that the manifestations of bullying occur mostly in the classroom $(6,1 \%)$. It was also observed that $32 \%$ said they had experienced a situation considered humiliating or embarrassing by teachers. Upon the findings of this research it was possible to affirm that the manifestations of bullying are present in social relations of the university.

Descriptors: Violence, Bullying, Higher Education.

\section{Conducta de estudiantes de la universidad de la amazonía frente a bullying}

El estudio tiene por objetivo investigar los casos de violencia en la relación de los académicos para conocer la prevalencia del maltrato entre iguales en la Universidad Federal de Rondónia- Campus, Puerto Viejo. Se trata de un estudio cuantitativo en que fue realizado un plan de investigación que ayudó a comprender las experiencias de violencia presentados por los estudiantes de educación superior de la ciudad en evidencia. Para la recogida de datos se utilizó un cuestionario validado que se aplicó durante las visitas a la Universidad, con estudiantes de diferentes cursos seleccionados por la cantidad muestra cuantitativa.456 entrevistas fueron realizadas. Los resultados mostraron que las manifestaciones de bullying se producen principalmente en las clases (6,1\%). También se observó que el 32\% dijeron que habían experimentado una situación que él consideraba humillante o embarazoso por parte de los docentes. Tras los resultados de esta investigación fue posible afirmar que las manifestaciones de bullying están presentes en las relaciones sociales de la universidad. Descriptores: Violencia, Bullying, Enseñanza Superior.

\section{INTRODUÇÃO}

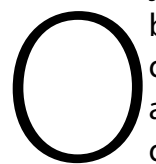

bullying é um tipo de violência presente nas instituições de ensino. É um fenômeno não tão recente, porém a preocupação com sua consequência é atual, detectada em meados da década de 1980. Nesse período ocorreram os primeiros estudos desenvolvidos por psicólogos e pedagogos ligados às instituições de ensino ${ }^{(1)}$. Portanto, o bullying é um fenômeno antigo, por se tratar de uma manifestação de violência que sempre existiu nas relações

1 Enfermeira. Doutora em Saúde Pública pela USP e docente do Departamento de Saúde Coletiva da Universidade Federal de Rondônia. Porto Velho, Rondônia, Brasil. 2 Discente do curso de Enfermagem da Universidade Federal de Rondônia, Porto Velho, Rondônia, Brasil.

3 Mestre em Matemática e docente do Departamento de Matemática da Universidade Federal de Rondônia. Porto Velho, Rondônia, Brasil.

4 Enfermeira. Doutora. Docente. Titular do Departamento de Enfermagem Materno-Infantil e Saúde Pública da Escola de Enfermagem de Ribeirão Preto - USP.

5 Enfermeiro. Mestrando em Saúde, Sociedade e Endemias na Amazônia pela UFAM/UFPA/Fiocruz-AM/ILMD.

6 Enfermeiro. Doutor em Enfermagem. Docente da Escola de Enfermagem da Universidade Federal do Amazonas-UFAM. Manaus-AM.

${ }^{*}$ Artigo produzido do projeto intitulado Bullying: Comportamento Agressivo Entre Estudantes em uma Capital da Região Amazônica. Projeto financiado pelo CNPq. 
desenvolvidas no cotidiano escolar, porém, é tratado de forma natural, pois não se trata de uma violência "explícita" como a agressão física e por isso é, na maioria das vezes, ignorado.

Os adolescentes envolvidos nesse tipo de violência, segundo vários estudos internacionais, não procuram nenhum auxílio ou ajuda com um profissional de saúde. O motivo principal é o sentimento de vergonha que a vítima experimenta por ter que admitir que apanhava ou sofria humilhações na escola ou ainda por medo de represálias do agressor ${ }^{(2)}$.

Nos ambientes universitários governados por pessoas insensíveis à violência, o bullying é visto como processo natural e comumente descartado. Atitudes abusivas por parte de docentes, que utilizam o recurso da avaliação para punir aqueles que pensam de forma diferente da imposta, são ignoradas - talvez por hierarquias ou por questões políticas. Muitos desses fenômenos acontecem de forma subjetiva, porém os resultados são reais e palpáveis, caracterizados por reprovações e principalmente em desistências do curso que em sua maioria foi ingressado através de muita luta e sacrifícios.

A ocorrência do bullying nas instituições de ensino superior merece maior investigação, pois durante muito tempo acreditava-se que estudantes universitários apresentavam maior capacidade de defesa. Ao contrário, percebe-se atualmente que estes sofrem abusos por parte de colegas e também da equipe docente, mas também agridem, ignoram, discriminam e, em alguns casos, até matam por não suportarem mais serem humilhados. Um exemplo bem conhecido é o trote universitário. Mesmo quando ocorre de forma solidária, não deixa de ser uma forma de bullying, em que a vítima muitas vezes o tolera para não ficar antipatizado pelo grupo. No Brasil, os primeiros trotes violentos aconteceram no século $X I X^{(3)}$.

Historicamente, podemos identificar diversos exemplos de bullying em todo o país e no mundo. Em 1831, um estudante foi morto a golpes de bengala durante trote na Universidade de Recife. Em 1850, os alunos da Faculdade de Direito do Largo São Francisco reagiram ao trote e a intervenção da polícia foi necessária para controlar a situação(3). Ao longo dos anos, as universidades vêm tentando alterar as práticas receptivas de novos alunos, porém os jornais e anais dessas instituições, ainda retratam situações de grande violência envolvendo trotes. Um dos casos que ganhou grandes proporções na mídia foi o de um estudante que morreu afogado durante trote realizado na piscina do campus da Faculdade de Medicina da USP em 1999(3).

Existem os casos envolvendo racismo que também levam os universitários a praticarem bullying(4). No Brasil, em 2007, supostos vândalos atearam fogo à porta do alojamento de quatro alunos africanos na Casa do Estudante Universitário (CEU), na Universidade de Brasília (UnB). Universitários bolsistas também são vítimas de constantes discriminações em universidades.

Os estudos acerca do tema bullying nas universidades ainda são escassos e é fundamental que recebam destaque para que haja maior entendimento do contexto desse fenômeno mundial. Propõe-se através deste estudo contribuir para a melhoria de referencial teórico para gerar subsídios para contribuir com o debate e discussão a fim de superar as dificuldades enfrentadas em relação ao bullying. Esta pesquisa faz parte de um estudo maior, multicêntrico, que envolveu universitários e escolares das cidades de Porto Velho-RO e de Ribeirão Preto-SP.

Assim, este trabalho teve como objetivo conhecer a prevalência de bullying dentro da Universidade Federal de Rondônia Campus Porto Velho, para identificar os atores, vítimas e o tipo de bullying ocorrido.

\section{METODOLOGIA}

Este trabalho é resultado do projeto de pesquisa intitulado Bullying: Comportamento Agressivo entre Estudantes em uma Capital da Região Amazônica, financiado em 2010 pelo Conselho Nacional de Desenvolvimento Científico e Tecnológico (CNPq). Estudo quantitativo, do tipo inquérito epidemiológico de delineamento das vivências de violência apresentadas por alunos do ensino superior da Universidade Federal de Rondônia, na cidade de Porto Velho.

O modelo de amostragem empregado foi de amostra estratificada proporcional realizada em duas etapas, sendo que os cursos constituem-se nas unidades do primeiro estágio, selecionados com probabilidade proporcional ao número de acadêmicos, enquanto que as unidades secundárias de amostragem são os acadêmicos de ensino selecionados com igual probabilidade. Os cursos foram estratificados em função dos núcleos. O software livre $\mathrm{R}$ foi utilizado para realizar as análises estatísticas. O erro amostral ficou no valor de 4,176\%.

Para constituição da amostra, os alunos sorteados foram organizados de acordo com o diário de classe. Para cada curso (A, B, $C, D / E, F, G, H, I, J)$ foram escolhidos 51 alunos, do mesmo modo de sorteio aleatório supracitado. Os cursos D e E ficaram juntos, pois pertencem a um mesmo núcleo e não completavam o número de alunos requerido, visto que muitos eram faltosos e desistentes.

O questionário utilizado foi validado e adaptado para a realidade local e possui questões que contextualizam as relações de violência entre discentes com os seguintes temas abordados: perfil socioeconômico: sexo, idade, pessoas com quem mora, escolaridade dos pais, trabalho do discente, estrato social (critério de classificação econômica da Associação Brasileira de Empresas de Pesquisa - $A B E P$ ), chamado Critério Brasil; procedência escolar; atividades esportivas; relacionamentos interpessoais e atitudes tomadas diante de situações conflituosas, entre outros.

Participaram do estudo discentes sorteados e regularmente matriculados nos cursos selecionados da UNIR. Foi apresentado um resumo do projeto e explicada a importância da realização para ter conhecimento da ocorrência ou não do fenômeno na instituição de ensino para os acadêmicos, para que desse seu parecer para participar da pesquisa. Como critério de exclusão os acadêmicos que faltaram no dia da aplicação dos questionários não participaram, e os que se recusaram tiveram seu direito acatado. Os participantes da pesquisa assinaram a autorização para a utilização das respostas através do Termo de Consentimento Livre e Esclarecido (TCLE).

OsquestionáriosforamaplicadosdurantevisitasàUniversidade, durantes os períodos selecionados, com atores sociais dos diversos cursos selecionados pela amostra quantitativa. Ao final, 
realizaram-se quatro visitas à UNIR, obtendo-se uma amostra de 456 entrevistas.

O banco de entrada de dados foi criado no programa Epi-info ${ }^{(3.5 .1)}$, cumprindo quatro rigorosas etapas durante o processamento: codificação, digitação, correção e análise. Os dados quantitativos foram inicialmente analisados através de descrição da frequência absoluta e relativa e do cruzamento de variáveis, que possibilitaram um conhecimento dos dados obtidos.

O projeto foi aprovado pelo Comitê de Ética do Núcleo de Saúde da Universidade Federal de Rondônia, conforme CAAE 0012.0.047.000 - 09 .

\section{RESULTADOS}

A amostra desta pesquisa definiu-se em 456 acadêmicos, distribuídos em dez cursos da universidade. No que concerne ao gênero, verificou-se que era composto de $57,3 \%$ representantes do sexo feminino e $42,7 \%$ do sexo masculino.

Em relação à faixa etária, os estudantes têm entre $17(6,4 \%)$ e 62 anos $(0,2 \%)$ nos cursos, com média de idade de 22,13 anos (DP \pm 6,26 anos).

Nesta pesquisa também foi observada a classificação socioeconômica dos discentes entrevistados. A tabela 1 demonstra a distribuição destes, segundo estrato social.

Tabela 1 - Distribuição dos acadêmicos da amostra segundo estrato social. Porto Velho - 2011.

\begin{tabular}{|l|c|c|}
\hline Classificação Econômica & N & $\%$ \\
\hline A1 & 10 & $2,2 \%$ \\
\hline A2 & 59 & $12,9 \%$ \\
B1 & 78 & $17,1 \%$ \\
B2 & 123 & $27 \%$ \\
\hline C1 & 112 & $24,6 \%$ \\
C2 & 57 & $12,5 \%$ \\
\hline D1 & 9 & $2 \%$ \\
E & 2 & $0,4 \%$ \\
\hline Não responderam & 6 & $1,3 \%$ \\
\hline TOTAL & $\mathbf{4 5 6}$ & 100 \\
\hline
\end{tabular}

No que diz respeito ao estrato social, verifica-se que $27 \%$ dos alunos estão inseridos na classe $B 2,24,6 \%$ na classe $\mathrm{C} 1$. As classes $\mathrm{A} 1$ e A2 juntas formam um percentual de $15,1 \%$ e as classes D1 eE $0,6 \%$.

A tabela 2 demonstra a ocorrência de bullying nos últimos três meses de aula dos participantes do estudo.

Tabela 2 - Distribuição dos acadêmicos segundo a indicação de ocorrência de agressão/assédio/prejuízo/intimidação nos últimos três meses de aula. Porto Velho - 2011.

\begin{tabular}{|l|c|c|}
\hline Número de vezes & N & $\%$ \\
\hline Nenhuma vez & 396 & 87 \\
\hline Uma ou duas vezes & 49 & 10,7 \\
\hline Três ou quatro vezes & 3 & 0,6 \\
Cinco vezes ou mais & 5 & 1,1 \\
\hline Não responderam & 3 & 0,6 \\
\hline TOTAL & 456 & 100 \\
\hline
\end{tabular}

Segundo os dados coletados, $87 \%$ dos discentes referem que não sofreram esse tipo de manifestação de violência nos últimos três meses, $10,7 \%$ referem que passaram uma ou duas vezes, $0,6 \%$ três ou quatro vezes e $1,1 \%$ referem cinco vezes ou mais. Quando questionados a respeito da forma como ocorre o bullying (os que referiram ter sofrido bullying), foram obtidos os seguintes resultados:

Tabela 3 - Tipificação das manifestações de bullying entre os acadêmicos. Porto Velho - 2011.

\begin{tabular}{|l|c|c|}
\hline Forma de ocorrência das situações & N & $\%$ \\
\hline Pegaram minhas coisas sem minha permissão & 5 & 7,3 \\
\hline Fizeram com que eu sentisse medo & 13 & 18,8 \\
\hline $\begin{array}{l}\text { Espalharam mensagens através da Internet } \\
\text { ou telefone para me prejudicar }\end{array}$ & 5 & 7,3 \\
$\begin{array}{l}\text { Ofenderam-me por causa da minha cor/raça } \\
\text { Falam a meu respeito escondido }\end{array}$ & 3 & 4,3 \\
Ninguém fala comigo & 32 & 46,4 \\
\hline TOTAL & 4 & 5,8 \\
\hline
\end{tabular}

Os resultados comprovam que as manifestações de bullying se caracterizam principalmente nos atos de falar a respeito escondido (46,4\%); em segundo, de que fizeram com que eu sentisse medo $(18,8 \%)$; colocar apelidos ou nomes que não gostei aparece em $10,1 \%$ dos casos e espalhar mensagens através da Internet para prejudicar ( $7,3 \%$ dos casos). Ofensas com relação à cor/raça dos estudantes foi identificada em $4,3 \%$ dos entrevistados.

A tabela 4 apresenta os dados obtidos referentes à manifestação de bullying segundo o local onde ocorrem.

Tabela 4 - Distribuição dos acadêmicos da amostra quanto ao local das ocorrências de bullying. Porto Velho - 2011.

\begin{tabular}{|l|c|c|}
\hline Variável & N & $\%$ \\
\hline Em nenhum lugar & 375 & 82,2 \\
\hline Nos corredores e/ou nas escadas & 23 & 5,1 \\
No pátio & 2 & 0,5 \\
Nas salas de aula & 28 & 6,1 \\
No refeitório e/ou cantina & 6 & 1,3 \\
No vestiário & 1 & 0,2 \\
\hline Em outro lugar & 14 & 3,1 \\
Não respondeu & 7 & 1,5 \\
\hline TOTAL & $\mathbf{4 5 6}$ & $\mathbf{1 0 0}$ \\
\hline
\end{tabular}

De acordo com os resultados acima, $82,2 \%$ dos acadêmicos afirmam que não ocorre em nenhum lugar, 6,1\% disseram que ocorre nas salas de aula, 5,1\% nos corredores e/ou escadas, 3,1\% dos entrevistados disse que ocorre em outro lugar.

A tabela 5 avalia a resposta dos acadêmicos da universidade a respeito de já terem ou não passado por alguma atitude considerada humilhante e/ou constrangedora por parte de um docente.

Dos estudantes entrevistados, observa-se que 32\% afirmam já 
ter passado por uma situação que consideraram humilhante e/ou constrangedora por parte dos professores. Para saber a respeito do tipo de situação passada pelos acadêmicos, também foram questionados quanto à forma da ocorrência da humilhação/ constrangimento.

Tabela 5 - Distribuição dos acadêmicos quanto à ocorrência de situação humilhante/constrangedora por parte dos docentes. Porto Velho - 2011.

\begin{tabular}{|l|c|c|}
\hline Variável & N & $\%$ \\
\hline Sim, já passei & 146 & 32 \\
\hline Não, nunca aconteceu & 307 & 67,3 \\
\hline Não respondeu & 3 & 0,7 \\
\hline TOTAL & 456 & 100 \\
\hline
\end{tabular}

A tabela 6 apresenta dados quanto ao local do acontecimento de situação que foi considerada humilhante ou mesmo constrangedora pelos estudantes entrevistados de acordo com a atitude dos docentes.

Tabela 6 - Distribuição dos acadêmicos quanto ao momento de ocorrência da situação humilhante/constrangedora por parte dos docentes. Porto Velho - 2011.

\begin{tabular}{|l|c|c|}
\hline Variável & N & $\%$ \\
\hline Em apresentação de trabalhos & 45 & 9,9 \\
\hline Na realização de prova & 12 & 2,6 \\
\hline Em algum momento, dentro da universidade & 11 & 2,4 \\
\hline Em sala de aula, na frente de outros acadêmicos & 46 & 10,1 \\
\hline Em sala de aula, na ausência de acadêmicos & 3 & 0,7 \\
\hline No campo de estágio & 5 & 1,1 \\
\hline Outro & 23 & 5,0 \\
\hline Não, nunca aconteceu & 311 & 68,2 \\
\hline TOTAL & 456 & 100 \\
\hline
\end{tabular}

Os resultados da tabela 6 mostram que em 10,1\% a situação constrangedora/humilhante ocorre em sala de aula, na frente de outros acadêmicos. Já 9,9\% marcaram que ocorre nas apresentações de trabalhos. Acadêmicos que optaram por marcar outro motivo correspondem a $5 \%$ dos pesquisados.

\section{DISCUSSÃO}

Nesta pesquisa foi observado que a amostra de estudantes demonstrou que há uma leve predominância do sexo feminino em relação ao masculino dos períodos entrevistados. Esse resultado pode ser esclarecido pelo fato de que as mulheres têm tido uma presença crescente em todos os níveis de ensino no Brasil. Consolidam-se como maioria a partir do ensino médio, dominam a graduação e detêm o maior número de bolsas de mestrado e doutorado no país, conforme aponta o estudo "Trajetória da Mulher na Educação Brasileira", trabalho, realizado pelo INEP (Instituto Nacional de Estudos e Pesquisas Educacionais Anísio Teixeira), MEC (Ministério da Educação) e a Secretaria Especial de Políticas para as Mulheres ${ }^{(5)}$.
Esse perfil diferenciado entre homens e mulheres na educação pode ser explicado pelas diferenças de acesso, a permanência e progressão no sistema de ensino, pela tendência a buscar o ingresso no mercado de trabalho, que pode ser motivado por necessidades econômicas da família, desinteresse por prosseguir nos estudos, e as expectativas socioculturais quanto ao papel de homem independente e produtivo ${ }^{(5)}$.

Quanto às ocorrências de bullying, o que tem maior evidência nas pesquisas é que em relação ao sexo é visto que meninos vitimaram mais que as meninas, além de se utilizarem mais da agressão física e verbal. As garotas, por seu turno, usariam mais a agressão indireta relacional, tal como espalhar rumores - "fofocas" - ou realizar exclusão social(6).

Com respeito à faixa etária, percebe-se que a média dos estudantes encontra-se com idade de 22 anos, caracterizando uma população jovem. Esses resultados são condizentes com as idades esperadas dos alunos para o Ensino Superior. Os acadêmicos acima de 35 anos encontrados demonstram que há o interesse pela busca de uma formação superior em uma idade que se espera estar atuante no mercado de trabalho.

Para identificar a classe socioeconômica dos acadêmicos foi aplicado o questionário da $A B E P$, pois várias pesquisas confirmam que nas instituições de ensino convivem alunos de diversas classes sociais e isso foi constatado através desta pesquisa.

Os dados contidos na tabela 1 mostram que a classificação econômica dos alunos universitários está mais concentrada nas classes B2 (27\%), C1 (24,6\%), e B1 (17,1\%) respectivamente. Estudos mostram que a presença das classes A e B na pesquisa podem estar relacionadas com o fato de os universitários poderem ainda residir com seus pais/outros familiares, (resultados mostram que $50,6 \%$ dos acadêmicos residem incluindo os mesmos - com três a quatro pessoas e $24,1 \%$ com o número de 5 a 6 pessoas) e as classes $\mathrm{D}$ e $\mathrm{E}$ podem ter relação com o número de universitários que moram sozinhos ou mesmo dividindo moradia com outros estudantes ${ }^{(7)}$.

Conforme encontrado nesta pesquisa, uma das características dos agressores - bullie - é criar apelidos, chamar de forma pejorativa as vítimas de maneira a constrangê-las e intimidá-las. Também foi verificado que há ocorrência de manifestações do fenômeno com utilização de meios como a Internet. Estudos mostram que, no Brasil, o cyberbullying é muito comum nas redes de relacionamento social, nas quais mensagens injuriosas são disseminadas rapidamente. É certo que a falsa sensação de anonimato e impunidade, características da internet, estimula muito esse tipo de comportamento ${ }^{(6)}$.

Através da prática do cyberbullying a vítima não ficará exposta apenas para um grupo limitado, mas será agredida e humilhada perante centenas de pessoas, que, por exemplo, poderão receber mensagens pelo correio eletrônico ou visualizar uma fotografia publicada na rede mundial de computadores e com isso o dano será intensificado.

Os dados apontam que há existência de preconceito racial, pois a ofensa quanto à cor e raça $(4,3 \%)$ não pode ser vista apenas como o bullying em si, pois constitui-se em crime com penalidade para os agressores. $\operatorname{Estudos}^{(3)}$ mostram que casos envolvendo racismo 
também levam os universitários a praticarem bullying, como mencionado anteriormente neste artigo.

De acordo com esta pesquisa, as manifestações de bullying são mais evidentes nos corredores e salas de aula, portanto um resultado semelhante ao de outro estudo ${ }^{(6)}$ onde foi visto no que tange aos lugares de ocorrência do bullying, que este é mais comum nos pátios e, especificamente, nos horários de intervalo (em que alunos podem permanecer no refeitório, corredores). Também é frequente o bullying diretamente nas salas de aula, inclusive com a presença de professores, situação que demonstra ser ainda comum a omissão desses profissionais no que se refere ao combate de tais formas de violência.

Um importante dado obtido nesta pesquisa foi o bullying praticado por professores. Em outras pesquisas ${ }^{(8)}$ foi visto que o bullying cometido por professores tem algumas semelhanças com o bullying entre pares. Também é um abuso de poder que tende a ser crônico e geralmente é expresso de forma pública. É uma forma de humilhação que gera atenção por degradar um aluno na frente dos outros. Com efeito, o bullying pode ser uma cerimônia pública de degradação, em que as capacidades da vítima são rebaixadas e sua identidade, ridicularizada.

Quanto à ocorrência dessa manifestação de violência por parte dos docentes, foi visto que ocorre principalmente nas salas de aula. Esses resultados corroboram com outros estudos ${ }^{(8)}$, nos quais os casos ocorrem na maioria em sala de aula, e relatam que $o$ professor que pratica o bullying geralmente não recebe nenhuma orientação quanto às consequências negativas de seus atos. A sala de aula é o local mais provável de ocorrência, embora possa ocorrer em qualquer local em que os alunos estão sob supervisão de outro em uma relação de forças desproporcional. Na mesma pesquisa, é relatado que a ameaça de danos no bullying por professores tende a ser não física, porém é invasiva e poderosa.
Como seres sociais, os humanos temem o isolamento e a humilhação tanto quanto (se não mais) o dano físico. Isso quer dizer que a ameaça de humilhação pode ser usada como uma arma. Os alunos que são alvo de professores podem se sentir numa armadilha onde quem abusa é todo-poderoso. Qualquer queixa sobre o comportamento abusivo coloca o aluno em risco de retaliação pelo professor, incluindo o uso das notas como sanção( ${ }^{(8)}$.

\section{CONCLUSÃO}

Mediante os achados foi possível afirmar que as manifestações de bullying estão presentes nas relações sociais da Universidade Federal de Rondônia. Elas ocorrem principalmente nas salas de aula, são praticadas tanto por agressores docentes como discentes. Um terço dos alunos entrevistados afirmou terem sidos constrangidos/humilhados por uma docente e isso ocorreu principalmente durante a apresentação de trabalhos e mediante outros acadêmicos.

$\mathrm{O}$ aprofundamento dos condicionantes e desencadeantes das manifestações de bullying foi analisado por meios de testes estatísticos, na busca de identificar associações de variáveis que possam, se não explicar, ao menos lançar luz para as causas que levaram aos resultados deste estudo-identificada a presença de manifestações de bullying em uma Instituição de Ensino Superior.

A realização de pesquisas tendo como foco de estudo o bullying no ensino superior ainda é escasso e os fatos expostos demonstram a necessidade de busca de alternativas para a melhora das relações sociais acadêmicas e é evidente a necessidade de fazer novas pesquisas para nortear medidas por parte do poder público para minimizar esse tipo de violência, o que contribui significativamente para subsidiar ações de prevenção de violência e controlar os possíveis problemas a serem encontrados.

\section{Referências}

1. Neto AAL. Diga não para o bullying. Programa de redução do comportamento

agressivo entre estudantes. Rio de Janeiro: ABRAPIA; 2004.

2. Fante CAZ. Fenômeno bullying: como prevenir a violência e educar para a paz. $2^{\mathrm{a}}$ ed. São Paulo: Verus; 2005.

3. Lima AAA. Fenômeno bullying na universidade [Internet]. [citado em 2011 Ago 10]. Disponivel em: http://www.artigonal.com/ensino-superior-artigos/fenomenobullying-na-universidade-688751.html

4. Secundo LCFV. Trote universitário e o fenômeno bullying. $2^{\mathrm{a}}$ ed. Rio de Janeiro: Impetus; 2007.

5. Ristoff D, Giolo J. Trajetória da mulher na educação superior brasileira: 1991 2004. Brasilia: Instituto Nacional de Estudos e Pesquisas Educacionais Anísio
Teixeira; 2006.

6. Albino LP, Terêncio GM. Consideraçōes críticas sobre o fenômeno do

bullying: do conceito ao combate e à prevenção. Rev Jur Minist Público Catarinense.2010;15:169-95.

7. Teschima HV, Marçal FA. Qualidade de vida percebida por estudantes universitários londrinenses [Internet]. [citado em 2011 Ago 03]. Disponível em: http://www.efdeportes.com/efd155/qualidade-de-vida-percebida-porestudantes.htm.

8. McEvoy A. Teachers who bully students: patterns and policy implications [Internet]. [citado em 2011 Ago 01]. Disponível em: http://gwired.gwu.edu/ hamfish/AnnualConference/2005/ 